\title{
LEISHMANIOSE NA ESCOLA: A PRESENÇA DA TEMÁTICA EM LIVROS DIDÁTICOS DO PNLD 2018 DE BIOLOGIA DO ENSINO MÉDIO
}

\section{LEISHMANIASIS IN SCHOOL: A THEMATIC APPROACH IN TEXTBOOKS OF PNLD MIDDLE SCHOOL BIOLOGY}

\author{
TEIXEIRA, Carlos Roberto Rodrigues ${ }^{1}$ \\ PEREIRA, Carlos Alberto Sanches ${ }^{2}$ \\ GUIMARÃES, Lucas Peres ${ }^{3}$ \\ PEREIRA, Ana Paula Cunha ${ }^{4}$
}

\begin{abstract}
RESUMO
A Leishmaniose é um grave problema de saúde pública no Brasil e no mundo. Os conhecimentos acerca desta doença são restritos, o que dissemina o potencial de infecção da mesma. O processo de ensino aprendizagem precisa estimular o debate dos aspectos sociais que determinam e condicionam a saúde individual e coletiva, e para tanto, recursos amplamente difundidos como os livros didáticos, precisam estar atualizados e preparados adequadamente para este feito. 0 presente estudo propõe uma análise da abordagem de Leishmaniose nos dez livros didáticos de Biologia do Ensino Médio, aprovados e recomendados pelo Programa Nacional do Livro Didático (PNLD) de 2018, a partir da perspectiva teórica e didático metodológica. Os métodos elencados para tal análise seguiram os seguintes critérios: delineamento prévio; categorização de análise dos livros didáticos; e apreciação, expressão dos resultados e interpretação. Os resultados apontam que embora trate-se de uma questão de saúde pública, os conteúdos programáticos e os aspectos didático metodológicos, não apresentam conteúdos suficientes para o ensino de Leishmanioses nos livros analisados.
\end{abstract}

Palavras chave: Leishmaniose; Ensino; Livro didático.

\begin{abstract}
Leishmaniasis is a serious public health problem in Brazil and worldwide. Knowledge about this disease is restricted, which spreads the potential for its infection. The teaching-learning process needs to stimulate debate on the social aspects that determine and condition individual and collective health, and for that, widespread resources such as textbooks need to be up to

${ }^{1}$ Centro Universitário de Volta Redonda (UniFOA) / Faculdade Sul Fluminense (FaSF). Volta Redonda, RJ, Brasil. ORCID: https://orcid.org/0000-0003-2389-3684 e-mail: carlosteixeirart@hotmail.com

2 Centro Universitário de Volta Redonda (UniFOA). Volta Redonda, RJ, Brasil. ORCID: https://orcid.org/0000-0002-6227-6198 e-mail: sanches68@gmail.com

3 Instituto Federal de Educação, Ciência e Tecnologia (IFRJ). Nilópolis, RJ, Brasil. ORCID: https://orcid.org/0000-0002-2226-3042 e-mail: lucaspegui@hotmail.com

4 Centro Universitário de Volta Redonda (UniFOA). Volta Redonda, RJ, Brasil. ORCID: https://orcid.org/0000-0002-2121-8469 e-mail: acunhapereiraa@gmail.com
\end{abstract}


DOI: $10.12957 / \mathrm{e}-\mathrm{mosaicos} .2020 .46139$

date and adequately prepared. This study proposes an analysis of the Leishmaniasis approach in the ten High School Biology textbooks, approved and recommended by the 2018 National Textbook Program, from the theoretical and methodological didactic perspective. The methods listed for this analysis followed these criteria: previous design; categorization of textbook analysis; appreciation, expression of results and interpretation. The results indicate that although it is a public health issue, the syllabus and the methodological didactic aspects do not present enough contents for the teaching of Leishmaniasis in the analyzed books.

KEYWORDS: Leishmaniasis; Teaching, Textbook.

\section{INTRODUÇÃO}

A Leishmaniose é um problema de saúde pública no Brasil. Trata-se de uma infecção crônica e sistêmica de transmissão vetorial que pode afetar tanto o homem quanto os cães. É causada pelo protozoário Leishmania e geralmente se apresenta de duas formas: a leishmaniose cutânea (LC), e a leishmaniose visceral (LV) sendo que a LV pode levar a óbito até 90\% dos casos (BRASIL, 2018).

Há um pouco mais de 20 anos que esta doença se configura como uma questão de saúde pública, conforme relata Desejeux (2001), as principais causas desse problema é a domesticação do ciclo de transmissão, a urbanização, o desmatamento, entre outros fatores. Um estudo efetuado em 1994 por Marzochi verificou que na Região Sudeste, a mais urbanizada do país, esta doença apresenta um caráter de transmissão domiciliar, pela adaptação do inseto vetor aos ambientes naturais modificados, possibilitando, desta forma, o envolvimento de animais domésticos como os cães e gatos. Corroborando com esses dados, Gama (1998), realizou uma pesquisa onde constatou que o conhecimento das pessoas com relação a leishmaniose era bem restrito. Nas regiões de sua ocorrência, como na Região Sudeste, e pela proximidade dos animais domésticos, as mulheres e as crianças estavam cada vez mais infectadas com a doença.

Vinte anos separam esses estudos da atualidade, e em nada esses dados se encontram defasados. No cotidiano, os cachorros estão cada vez mais próximos dos seres humanos. Segundo Tatibana e Costa-Val (2009), a civilização moderna isolou os seres humanos cada vez mais uns dos outros, e por isto a procura pela companhia de cães como animais de estimação cresceu muito. Em muitos casos, os cães assumiram grande importância na saúde mental e até mesmo física das pessoas, passando a ser considerados membros da família. Entretanto, segundo relata Brasil (2019), o cão é o principal reservatório do parasito em área urbana. Neles, o tratamento pode até resultar no desaparecimento dos sinais clínicos, porém continuam como fontes de infecção para o vetor, e, portanto, um risco para saúde da população humana e canina.

Devido à falta de informação com relação à Leishmaniose e o grave problema de saúde pública, é importante que a escola comece a pensar em algumas ações para o trabalho dessa temática, como corrobora Sousa e Guimarães (2017), quando 
DOI: $10.12957 /$ e-mosaicos.2020.46139

afirmam que no que se refere à saúde, a escola cumpre o seu papel formador ao colocar em debate os aspectos sociais que determinam e condicionam a saúde individual e coletiva. Ações educativas direcionadas a uma formação cidadã com um saber prescritivo capaz de criar uma conscientização de combate e prevenção, proporciona a autonomia dos estudantes.

Para moderar essas ações, o professor precisa agregar recursos compatíveis e atualizados sobre a questão. Um dos instrumentos mais utilizados, e que se mostra como o recurso mais acessível a todos, são os livros didáticos. Existem escolas com mais, e outras com menos recursos, mas todas são contempladas com o livro didático. As escolas públicas da Educação Básica, recebem esses livros do Programa Nacional do Livro Didático (PNLD) para instrumentar suas práticas docentes. O professor se embasa nesse recurso como ponto de partida para elaborar estratégias pedagógicas para enriquecer a abordagem dos conteúdos que trabalha em sala de aula (NICOLA; PANIZ, 2016; MODELSKI, 2018).

Entretanto, de acordo com Reis, Albuquerque e Soares (2014), em uma análise efetuada dos livros didáticos recomendados de 2010, verificou-se a ausência de imagens ou ilustrações, quadros comparativos além da distinção entre as formas clínicas da doença, ou aspectos da transmissão, o que pode levar às concepções errôneas acerca dos mecanismos da transmissão e controle e dificultar a aprendizagem.

O Ministério da Educação preconiza que a avaliação do livro didático é uma resposta ao compromisso com a melhoria e ampliação dos recursos didáticos disponíveis para o trabalho docente e para o efetivo apoio ao desenvolvimento intelectual do aluno (BRASIL, 2008). Sabendo da necessidade da abordagem adequada da leishmaniose na escola e que para isso, serão necessários recursos para o trabalho docente, esse trabalho se propõe a examinar os livros didáticos mais atuais de Biologia através da categorização da linguagem científica, contextualização do conteúdo, ilustração e os exercícios de consolidação.

Sendo assim, o objetivo do estudo consiste em analisar a abordagem de Leishmaniose, em livros didáticos comumente utilizados para o ensino de Biologia no Ensino Médio, que foram aprovados e recomendados pelo Programa Nacional do Livro Didático (PNLD) de 2018.

\section{MetOdOLOGIA}

Trata-se de um estudo de base qualitativa, desenvolvido com integridade ética amparado nas normas de conduta e premissas éticas do 'Código de Boas Práticas Científicas' da Fundação de Amparo à Pesquisa do Estado de São Paulo - FAPESP (BRASIL, 2014).

O estudo foi estruturado adotando critérios metodológicos para sistematizar e organizar a análise conforme demonstra a Figura 1, especificando cada item na sequência: 
DOI: $10.12957 / \mathrm{e}-\mathrm{mosaicos} .2020 .46139$

Figura 1 - Critérios metodológicos do estudo

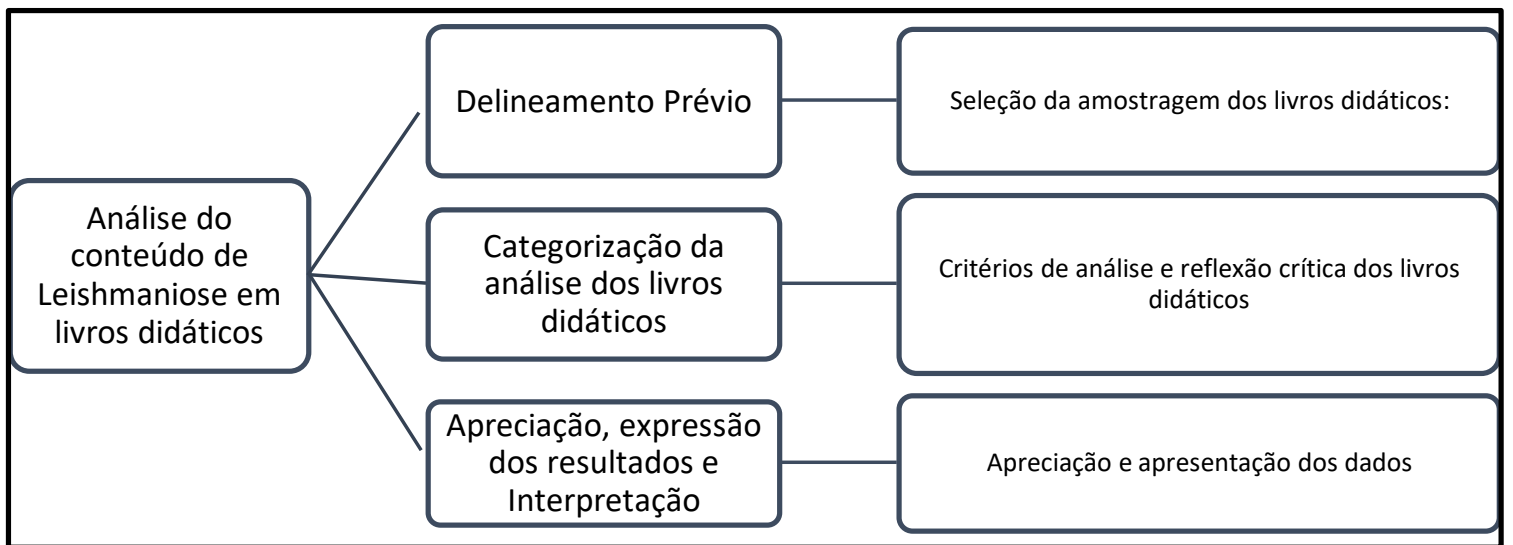

Fonte: Os autores (2019).

Conforme apresentado na figura 1, o delineamento Prévio do estudo abrangeu a Seleção dos livros didáticos. Dessa forma, a amostragem dos livros foi selecionada com base nas obras didáticas de Biologia que foram aprovadas e recomendadas pelo Programa Nacional do Livro Didático para o Ensino Médio (PNLDEM) de 2018, que constam no Guia de livros didáticos: Ensino Médio - Biologia. Nesse documento, são apresentadas uma visão geral e uma resenha crítica de dez coleções didáticas de Biologia, sendo compostas por 3 volumes em cada uma delas: um volume para cada ano do Ensino Médio.

De acordo com Germinari e Moura (2017), os livros didáticos selecionados pelo PNLD são amplamente distribuídos em todo território nacional, chegando a milhares de professores e alunos. Sobre a escolha e seleção dos autores recomendados pelo Programa, os autores frisam que:

O PNLD dá aos profissionais envolvidos com o ensino a oportunidade de escolher a obra a ser utilizada na sala de aula. Uma tarefa muito importante que exige seriedade dos docentes, na medida em que a escolha errada pode dificultar e/ou comprometer a aprendizagem dos alunos. Por isto, os professores têm que encontrar critérios de seleção, os quais permitam a melhor escolha, para que sejam alcançadas as aprendizagens condizentes com as expectativas da disciplina e também da própria sociedade (GERMINARI; MOURA, 2017, p.103).

Foram analisados no presente estudo os volumes cujo conteúdo de Leishmaniose é abordado nas 10 autorias sugeridas pelo PNLD 2018, que se encontram listadas na Figura 2. 
DOI: $10.12957 / \mathrm{e}-\mathrm{mosaicos} .2020 .46139$

Figura 2 - Livros didáticos selecionados para análise

\begin{tabular}{|c|c|}
\hline LIVRO A & $\begin{array}{l}\text { - Biologia Moderna - Amabis \& Martho. Moderna. } 1^{\text {a }} \text { Ed. 2016. Vol. } 2 \\
\text { - Autores: Gilberto Rodrigues Martho; José Mariano Amabis }\end{array}$ \\
\hline LIVRO B & $\begin{array}{l}\text { - Biologia Hoje. Editora Ática. } 3^{a} \text { Ed. } 2016 \text { - Vol. } 2 \\
\text { - Autores: Fernando Gerwandsznajder, Sérgio Linhares e Helena Pacca }\end{array}$ \\
\hline LIVRO C & $\begin{array}{l}\text { - Biologia - Unidade e Diversidade. FTD. 1a Ed. 2016. Vol. } 2 \\
\text { - Autores: José Arnaldo Favaretto }\end{array}$ \\
\hline LIVRO D & $\begin{array}{l}\text { - Biologia. AJS. 3a Ed. 2016. Vol. } 2 \\
\text { - Autores: Vivian L. Mendonça }\end{array}$ \\
\hline LIVRO E & $\begin{array}{l}\text { - Integralis - Biologia: novas bases. IBEP. } 1^{\text {a }} \text { Ed. 2016. Vol. } 2 \\
\text { - Autores:Nélio Bizzo }\end{array}$ \\
\hline LIVRO F & $\begin{array}{l}\text { - Ser Protagonista - Biologia. SM. 3a Ed. 2016. Vol. } 2 \\
\text { - Autores: André Catani, et al. }\end{array}$ \\
\hline LIVRO G & $\begin{array}{l}\text { - Conexões com a Biologia. Moderna. } 2^{\text {a }} \text { Ed. 2016. Vol. } 3 \\
\text { - Autores: Obra coletiva. Editora Rita Helena Bröckelmann }\end{array}$ \\
\hline LIVRO H & $\begin{array}{l}\text { - Bio. Moderna. } 3^{a} \text { Ed. 2016. Vol. } 2 \\
\text { - Autores: Sônia Lopes e Sérgio Rosso }\end{array}$ \\
\hline LIVRO I & $\begin{array}{l}\text { - Biologia. Saraiva. 12a Ed. 2016. Vol. } 2 \\
\text {-Autores: César da Silva Junior, Sezar Sasson, Nelson Caldini Junior }\end{array}$ \\
\hline LIVRO J & $\begin{array}{l}\text {-\# Contato Biologia. Quinteto. } 1^{\text {a }} \text { Ed. 2016. Vol. } 2 \\
\text {-Autores: Marcela Yaemi Ogo e Leandro Pereira de Godoy }\end{array}$ \\
\hline
\end{tabular}

Fonte: Os autores (2019). Extraído PNLD 2018. Guia de Livros didáticos Ensino Médio (BRASIL, 2017)

Em relação à categorização da análise dos livros didáticos (figura 1), a análise das obras contempladas está estruturada em duas vertentes principais: a primeira verifica se esses principais conteúdos acerca Leishmaniose estão adequadamente representados nos livros. Os tópicos aferidos são: vetor, parasito, ciclo evolutivo, forma da doença, epidemiologia, diagnóstico, tratamento e profilaxia. A segunda vertente observa se o aspecto didático metodológico está pertinente para processo de ensino aprendizagem da Leishmaniose, sendo esses quesitos: Linguagem científica, Contextualização do conteúdo, Ilustração e Representação esquemática, Exercícios de consolidação.

O parâmetro de análise, desses últimos tópicos, foi norteado pelas seguintes questões indagativas, relatadas na Tabela 1: 
DOI: $10.12957 / \mathrm{e}-\mathrm{mosaicos} .2020 .46139$

Tabela 1 - Questões parâmetros para análise dos aspectos didático metodológicos

Tópicos didático metodológicos

Linguagem Científica

\section{Questões parâmetros que norteiam a análise}

A linguagem científica está adequada ao desenvolvimento cognitivo do discente?

O conteúdo está exposto de modo que contextualize com a realidade do discente?

conteúdo

Ilustração e

representação

esquemática

- As ilustrações representam adequadamente o que está sendo representado?

- Os esquemas dos principais processos estão elaborados corretamente?

Exercícios de consolidação
As atividades propostas auxiliam os alunos a apreender os conhecimentos científicos dispostos na obra?

Fonte: Os autores (2019).

Neste sentido, a linguagem científica é carregada de particularidades específicas e, além disso, é uma forma de registrar e ampliar o conhecimento. De acordo com Oliveira (et al. 2009, p.22), "merecem uma particular atenção, pois interfere na compreensão de conceitos científicos. $O$ domínio da linguagem pelo aluno transformase num valioso instrumento de desenvolvimento dos processos cognitivos e orienta a construção do próprio conhecimento".

O Programa Nacional do Livro para o Ensino Médio (BRASIL, 2009) frisa que contextualizar é a palavra de ordem no ensino, que os textos precisam oportunizar ao docente e discente. A contextualização de conteúdo é destaque nas orientações iniciais do Guia de Livros didáticos do Ensino Médio que menciona neste aspecto:

Os livros didáticos atuais se desenvolveram muito, focando em interessantes articulações entre as Ciências Biológicas, nossa Ciência de referência, e a vida, em suas muitas dimensões (social, cultural, política etc.). Assim, abrem-se muitas possibilidades de uso desses materiais, na busca por inovar e projetar ambientes educativos que dialoguem efetivamente com as necessidades formativas de nossos estudantes, em uma sociedade que se desenvolve e se transforma continuamente, produzindo novas e importantes problemáticas (BRASIL, 2017).

A ilustração e a representação esquemática ressaltam a imagem não apenas como adereço, mas como uma fonte na construção de uma imagem mais próxima da 
compreensão do aluno. Para Coutinho et al. (2010), as imagens constituem um meio amplamente aceito no diálogo científico, tendo um potencial particular para comunicar aspectos da natureza e para indicar o conteúdo de ideias. Os exercícios de consolidação funcionam como termômetro entre o aluno e professor, capaz de medir grau de conhecimento absorvido.

Por último, a análise interpretativa dos dados (figura 1) baseou-se nos tramites a seguir: a apreciação atribuída a cada um dos tópicos aferidos expressa a contemplação dos objetivos do ensino de Leishmaniose. A mesma foi efetuada atribuindo uma nota que vai de $\varnothing$ à 4 , sendo $\varnothing$ - nada consta, a menor apreciação que significa que aquele tópico não contempla o objetivo do ensino; 1 contempla $\cong$ $25 \%$ do objetivo do ensino; 2 contempla $\cong 50 \%$ do objetivo do ensino; 3 contempla $75 \%$ do objetivo do ensino; e 4 que é a maior apreciação contempla $100 \%$ do objetivo do ensino. Outro ponto relevante é que, a interpretação proveniente dessa apreciação se exemplifica nas situações descritas a seguir: Nos tópicos referentes ao "conteúdo", ou seja, na análise teórica dos livros, se algum dos tópicos aferidos receber a apreciação $\emptyset$ significa que esta etapa do desenvolvimento não está contemplada no livro indicado; se receber a apreciação 3 significa que $\cong 75 \%$ do que deveria ser ensinado desta etapa está contemplado naquele referido livro. De modo similar, se algum dos tópicos didático metodológicos, tomando como exemplo o de 'Contextualização do conteúdo' receber a apreciação $\emptyset$, significa que não contempla o objetivo do ensino, ou seja, o conteúdo não está exposto de modo a contextualizar com a realidade; se receber a apreciação 2 , significa que contempla $\cong 25 \%$ de contextualização com a realidade do discente.

\section{Resultado e discussão}

A análise do conteúdo de Leishmaniose, quanto aos aspectos didáticos metodológicos e de conteúdos programáticos (saberes científicos teóricos), utilizada nos livros de Biologia do Ensino Médio, é representada através da Tabela 2, e sua respectiva legenda representada através da Tabela 3.

Tabela 2 - Análise didática e de conteúdos de Leishmaniose dos Livros didáticos de Biologia

\begin{tabular}{|c|c|c|c|c|c|c|c|c|c|c|c|}
\hline \multirow{2}{*}{\multicolumn{2}{|c|}{ Tópico aferido }} & \multicolumn{10}{|c|}{ LIVROS DIDÁTICOS (LD) } \\
\hline & & A & B & C & D & $\mathbf{E}$ & $\mathbf{F}$ & G & $\mathbf{H}$ & I & J \\
\hline \multirow{8}{*}{$\begin{array}{l}\text { 总 } \\
\text { 岁 } \\
\text { 号 }\end{array}$} & Vetor & 4 & 4 & 4 & 4 & 4 & 4 & 4 & 4 & 4 & 4 \\
\hline & Parasito & 4 & 4 & 4 & 4 & 4 & 4 & 4 & 4 & 4 & 4 \\
\hline & Ciclo Evolutivo & 0 & 1 & 0 & 0 & 2 & 0 & 0 & 0 & 0 & 4 \\
\hline & Formas da Doença & 4 & 4 & 4 & 2 & 4 & 4 & 2 & 4 & 2 & 0 \\
\hline & Epidemiologia & 0 & 0 & 0 & 0 & 3 & 0 & 0 & 0 & 0 & 0 \\
\hline & Diagnóstico & 0 & 0 & 0 & 0 & 1 & 0 & 0 & 0 & 0 & 0 \\
\hline & Tratamento & 0 & 0 & 0 & 0 & 1 & 0 & 0 & 0 & 0 & 0 \\
\hline & Profilaxia & 2 & 1 & 1 & 0 & 1 & 0 & 1 & 1 & 0 & 0 \\
\hline \multirow{4}{*}{ 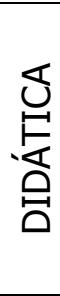 } & Linguagem científica & 4 & 4 & 4 & 2 & 4 & 4 & 4 & 4 & 2 & 2 \\
\hline & Contextualização & 1 & 0 & 0 & 0 & 3 & 0 & 0 & 0 & 0 & 0 \\
\hline & $\begin{array}{l}\text { Iconografia: lustração e } \\
\text { Rep. esquemática }\end{array}$ & 0 & 0 & 0 & 0 & 0 & 0 & 0 & 0 & 0 & 0 \\
\hline & $\begin{array}{l}\text { Exercícios de } \\
\text { consolidação }\end{array}$ & 0 & 0 & 0 & 0 & 0 & 0 & 0 & 1 & 0 & 1 \\
\hline & SOMATÓRIO GERAL & 19 & 18 & 17 & 12 & 27 & 16 & 14 & 17 & 06 & 15 \\
\hline
\end{tabular}


Tabela 3 - Legenda

\begin{tabular}{c|c}
\hline Apreciação & \multicolumn{1}{c}{ Interpretação } \\
\hline$\varnothing$ & Não contempla o objetivo do ensino \\
\hline 1 & Contempla $\cong 25 \%$ do objetivo do ensino \\
\hline 2 & Contempla $\cong 50 \%$ do objetivo do ensino \\
\hline 3 & Contempla $\cong 75 \%$ do objetivo do ensino \\
\hline 4 & Contempla $100 \%$ do objetivo do ensino \\
\hline
\end{tabular}

Fonte: Os autores (2019).

\section{SOBRE A ADEQUAÇÃO TEÓRICA DOS CONTEÚDOS DE LEISHMANIOSE NOS LIVROS DIDÁTICOS}

No que se refere à adequação teórica dos conteúdos de Leishmaniose nos livros didáticos analisados, as características gerais dos seres vivos são abordadas previamente porém de forma sucinta, e que servem de suporte para compreensão de algumas doenças, dentre elas as leishmanioses.

Em relação aos conteúdos de Leishmaniose contidos nos livros didáticos analisados, as abordagens se restringem a um ou dois parágrafos, dentro dos capítulos que tratam dos Protoctistas, com ênfase na identificação do vetor, o parasito e as formas da doença. Ou seja, as obras concedem uma maior ênfase a que o aluno conheça qual é o vetor, o agente etiológico e as formas de apresentação da Leishmaniose. Destaque para os tópicos vetor e parasito, cujos dez livros analisados contemplam a $100 \%$ do objetivo a ser ensinado. No tópico formas da doença, seis contemplam $100 \%$ do objetivo que deve ser ensinado, três contemplam somente $\cong 50 \%$ do objetivo e um nada contempla.

No tópico ciclo evolutivo, somente o "livro J" apresenta $100 \%$ do objetivo a ser ensinado, o "livro $\mathrm{B}^{\prime \prime}$ apresenta $\cong 25 \%$, o "livro $\mathrm{E}^{\prime \prime} \cong 50 \%$, e os demais livros nada apresentam. No tópico profilaxia, os "livros A, B, C, E, G e H" apresentaram pequeno conteúdo, e os "livros D, F, I e J" nada apresentaram. Nas dez obras analisadas, somente o "livro $\mathrm{E}^{\prime \prime}$ apresenta $\cong 25 \%$ conteúdo de ensino no que se refere ao diagnóstico e tratamento da doença de Leishmaniose. Somente o "livro E" contempla o tópico epidemiologia com $\cong 75 \%$ do objetivo que deve ser ensinado e nove obras nada apresentam em relação a este tópico.

Os Parâmetros Curriculares Nacionais - Saúde, preconiza que: "ao falar de educação, fala-se de articular conhecimentos, atitudes, aptidões, comportamentos e práticas pessoais que possam ser aplicados e compartilhados com a sociedade em geral. Nessa perspectiva, o processo educativo favorece o desenvolvimento da autonomia, ao mesmo tempo em que atende a objetivos sociais" (Brasil, 1998, pág. 259). 
DOI: $10.12957 / \mathrm{e}-\mathrm{mosaicos} .2020 .46139$

\section{SOBRe A PERTINÊnCIA didÁtico METOdológica dOS LIVROS AO ABORDAR A LEISHMANIOSE}

Dos dez livros analisados, os "livros A, B, C, E, F, G e H" foram apreciados positivamente quanto à linguagem científica utilizada, no que diz respeito à sua adequação de $100 \%$ de alcance ao desenvolvimento cognitivo do discente. Os "livros $\mathrm{D}$, I e $\mathrm{J}^{\prime \prime}$ alcançam $\cong 50 \%$ do objetivo. A linguagem científica tem particularidades específicas, e em concordância com Oliveira (et al. 2009, p. 22) "merecem uma particular atenção, pois interfere na compreensão de conceitos científicos. O domínio da linguagem pelo aluno transforma-se num valioso instrumento de desenvolvimento dos processos cognitivos e orienta a construção do próprio conhecimento".

No que se refere ao tópico de Contextualização do conteúdo, o "livro E" apresenta $\cong 75 \%$ de conteúdo com a realidade do aluno, o "livro $A^{\prime \prime}$ apresenta $\cong 25 \%$ e os demais livros nada apresentam. Conforme Ricardo (2005), a contextualização parte da realidade e a ela retorna com um novo olhar de compreensão e ação.

Destaque negativo para os tópicos ilustrações e representações esquemáticas das principais estruturas e exercícios de consolidação dos conhecimentos, pois nada foi encontrado nos livros analisados. De acordo com Gazzinelli, Reis e Marques (2006), a imagem no campo educacional permite vincular o conteúdo estudado, permitindo que o aluno, ao ter suas sensações estimuladas, parta do campo cognitivo do processo de ensino-aprendizagem para o registro da realidade.

Em relação aos exercícios de consolidação, somente os "livros $\mathrm{C}, \mathrm{E}, \mathrm{H}$ e J" apresentam $\cong 25 \%$ do objetivo proposto, com uma atividade proposta para auxiliar os alunos a apreender os conhecimentos dispostos na obra. Segundo Carvalho, et al. (2001), a educação em saúde torna-se uma construção compartilhada de conhecimento, quando parte para a experiência e prática dos sujeitos envolvidos, buscando interver nas relações sociais que influenciam na qualidade de suas vidas.

De um modo geral, a organização e planejamento didático metodológico dos livros foi assinalada como insuficiente para garantir uma boa condução do ensino de Leishmanioses em sala de aula. Segundo Nicola e Paniz (2016), muitas das vezes o professor utiliza-se do livro didático como única ferramenta para ensino em sala de aula, deixando de incorporar outras ferramentas para auxiliar os alunos na aprendizagem dos conteúdos. Para Bernardo e Tavares (2017, p. 90), "a falta de planejamento e uma má compreensão sobre o real significado de didática pode interferir no processo de ensino-aprendizagem".

Corroborando com esse pensamento, Silva e Felício (2017) destacam que é na construção de um conhecimento aprofundado desse processo de ensino e aprendizagem que devem fazer-se emergir os saberes docentes. Frisa-se, deste modo, a importância de uma formação docente inicial e continuada, que sustente a diversidade de conhecimentos profissionais necessários para uma intervenção profissional, informada e coerente. 
DOI: $10.12957 / \mathrm{e}-\mathrm{mosaicos} .2020 .46139$

\section{CONSIDERAÇÕES FINAIS}

Percebe-se que a leishmaniose foi pouco abordada nos livros analisados. A maior incidência de informações está para a forma da doença, o vetor e o agente etiológico. Em relação ao ciclo evolutivo, diagnóstico, tratamento e profilaxia da doença há pouca ou nenhuma abordagem. Outro fator importante a destacar, é a insuficiência de imagens ilustrativas para melhor compreensão por parte do aluno e a falta de contextualização do assunto com a sua realidade. O livro didático de biologia, deve ser percebido como uma importante ferramenta que auxilie no processo de ensino e aprendizagem e leve o aluno a pensar, refletir e compreender o conhecimento que a ele está sendo transmitido. Sob a ótica da didática, necessita apresentar conteúdos com informações suficientes para que o aluno caminhe com segurança na construção da aprendizagem, e promova uma constante reflexão do seu comportamento social e de seu papel como agente transformador no combate e controle das doenças.

No intuito de formar cidadãos atuantes e comprometidos com as questões sociais e de saúde, sugere-se que as escolas trabalhem a doença, utilizando-se de pesquisas complementares e projetos sociais, de forma a mobilizar os alunos e envolver a comunidade do entorno, direcionando a atenção destes para a importância de se conhecer a doença, e as formas de sua prevenção.

Embora observe-se que, em relação ao ensino da Leishmaniose, as obras analisadas forneçam pouco conteúdo programático e o aspecto didático metodológico seja deficitário, espera-se que este estudo, através da análise crítica efetuada e discussões estabelecidas, sirva para chamar a atenção para a necessidade da oferta de conteúdos mais ricos e didaticamente elaborados para o Ensino de Leishmaniose na Educação Básica, bem como contribua para a construção coletiva do acervo científico.

\section{REFERÊNCIAS}

AMABIS, José Mariano; MARTHO, Gilberto Rodrigues. Biologia Moderna: Amabis \& Martho. V. 1, 1. ed, Ensino Médio, São Paulo: Moderna, 2016.

BIZZO, Nelio. Biologia: novas bases. Vol. 1, 1. ed. São Paulo: IBEP, 2016.

BRASIL. Biologia: catálogo do Programa Nacional do Livro para o Ensino Médio:

PNLEM/2009. Secretaria de Educação Básica, Fundo Nacional de Desenvolvimento da Educação. Brasília: Ministério da Educação, Secretaria de Educação Básica, 2008. 108 p.

BRASIL. Código de Boas Práticas Científicas. Fundação de Amparo à Pesquisa do Estado de São Paulo - FAPESP. Secretaria de Desenvolvimento Econômico, Ciência e Tecnologia. Governo de São Paulo: FAPESP. 2014. 48p. 
DOI: $10.12957 / \mathrm{e}-\mathrm{mosaicos} .2020 .46139$

BRASIL. Ministério da Educação. PNLD 2018: Biologia - guia de livros didáticos Ensino Médio. Secretária de Educação Básica - SEB - Fundo Nacional de Desenvolvimento da Educação. Brasília, DF: Ministério da Educação, Secretária de Educação Básica, 2017. 9 p.

BRASIL, Ministério da Saúde. Leishmaniose Visceral: o que é, causas, sintomas, tratamento, diagnóstico e prevenção. Publicado em 16 Ago. 2019. Disponível em:

http://saude.gov.br/saude-de-a-z/leishmaniose-visceral Acesso em: 05 out. 2019.

BRASIL. Parâmetros curriculares nacionais: terceiro e quarto ciclo; apresentação dos temas transversais. Brasília: MEC/SEF, 1998. 436 p.

CARVALHO, M.A.P, ACIOLI, S. Stotz, E.N. O processo de construção compartilhada do conhecimento: uma experiência de investigação do ponto de vista popular. In: VASCONCELOS, E.M, organizador. A saúde nas palavras e nos gestos: reflexões da rede popular e saúde. São Paulo: Editora Hucitec: 2001. p.101-44.

CATANI, André; CARVALHO, Elisa Garcia; SANTOS, Fernando Santiago dos; AGUILAR, João Batista; CAMPOS, Sílvia Helena de Arruda. Ser Protagonista: biologia. $2^{\circ}$ ano: Ensino Médio. 3. ed. São Paulo: Edições SM, 2016.

COUTINHO, F. A. et al. Análise do valor didático de imagens presentes em livros de Biologia para o ensino médio. Revista Brasileira de Pesquisa em Educação em Ciências, São Paulo, v. 10, n. 3. 2010.

DESJEUX $\mathrm{P}$. The increase in risk factors for leishmaniasis worldwide. Trans $\mathrm{R}$ Soc Trop Med Hyg, 2001.

FAVARETTO, José Arnaldo. Biologia unidade e diversidade. $1^{\circ}$ ano, 1. ed., São Paulo: FTD, 2016.

GAMA MEA, BARBOSA JS, PIRES B, CUNHA AKB, FREITAS AR, RIBEIRO IR. Avaliação do nível de conhecimento que populações residentes em áreas endêmicas têm sobre leishmaniose visceral, estado do Maranhão, Brasil. Caderno de Saúde Pública, 1998.

GAZZINELLI, M. F., REIS, C., MARQUES, R.C. Educação em saúde: teoria, método e imaginação. Belo Horizonte: UFMG, 2006. 167 p.

GERMINARI, Geyso D.; MOURA, Anderson Fagundes de. Livro didático de história, entre conteúdos e epistemologia. Vol. 21, no.1, Educação Unisinos, p. 102-110, Jan./Abr., 2017. Disponível em: revistas.unisinos.br/index.php/educacao/article/view/ edu.2017.211.11 Acesso em: 09 out. 2019

LINHARES, Sérgio; GERWANDSZNAJDER, Fernando; PACCA, Helena. Biologia Hoje. Vol. 1, 3. ed., São Paulo: Editora Ática, 2016.

LOPES, Sônia; ROSSO, Linhares. Bio. Vol.2, 3. ed., São Paulo: Saraiva, 2016. 
DOI: $10.12957 / \mathrm{e}-\mathrm{mosaicos} .2020 .46139$

MARZOCHI MCA, MARZOCHI KBF. Tegumentary and visceral leishmaniasis in Brazil emerging anthropozoonosis and possibilities for their control. Caderno de Saúde Pública, 1994.

MENDONÇA, Vivian L. Biologia: Ecologia: Origem da vida e biologia celular: embriologia e histologia. Vol. 1, 3. ed., Ensino Médio. São Paulo: Editora AJS, 2016.

MODELSKI, Daiane; AZEREDO, Isabel; GIRAFFA, Lucia. Formação docente, práticas pedagógicas e tecnologias digitais: Reflexões ainda necessárias. Revista

Pesquiseduca, v. 10, n. 20, p. 116-133, Jan.-Abr. 2018. Disponível em: http://periodicos.unisantos.br/index.php/pesquiseduca/article/view/678 Acesso em: 12 abr. 2019.

NICOLA, Jéssica Anese; PANIZ, Catiane Mazocco. A importância da utilização de diferentes recursos didáticos no ensino de Biologia. Inovação e Formação, Rev. NEaD-Unesp, São Paulo, v. 2, n. 1, p. 355-381, 2016. Disponível em: https://ojs.ead.unesp.br/index.php/nead/article/view/InFor2120167 Acesso em: 05 out. 2019.

OGO, Marcela Yaemi; GODOY, Leandro Pereira de. \#Contato Biologia, 10 ano. Ensino Médio, 1. ed., São Paulo: Quinteto Editorial, 2016.

OLIVEIRA, Silmara Sartoreto; GUERREIRO, Lariza Borges; BONFIM, Patrícia Mendes. Educação para a saúde: a doença como conteúdo nas aulas de ciências. Hist. cienc. saude-Manguinhos, Rio de Janeiro , v. 14, n. 4, p. 1313-1328, Dec. 2007. Disponível em: http://www.scielo.br/scielo.php?script=sci_arttext\&pid=S010459702007000400011\&lng=en\&nrm=iso Acesso em: 24 out. 2019.

OLIVEIRA, Teresa; FREIRE, Ana; CARVALHO, Carolina; AZEVEDO, Mário; FREIRE, Sofia; BAPTISTA, Mónica. Compreendendo a aprendizagem da linguagem científica na formação de professores de ciências. Revista Educar, Curitiba, n. 34, p. 19-33, 2009. Editora UFPR. Disponível em: www.scielo.br/pdf/er/n34/02.pdf Acesso em: 22 abr. 2019.

REIS, Debora Batista; ALBUQUERQUE, Tatiana Saboya; SOARES, Maria Regiane Araujo. As Leishmanioses e o livro didático: como as doenças endêmicas são abordadas no ensino público? Revista Investigações em Ensino de Ciências - V19(1), pp. 91-98, 2014. Disponível em:

https://www.if.ufrgs.br/cref/ojs/index.php/ienci/artcle/view/97/68 Acesso em:10 out. 2019

RICARDO, Elio. Competências, Interdisciplinaridade e Contextualização: dos Parâmetros Curriculares Nacionais a uma compreensão para o ensino das ciências. Tese de Doutorado, PPGECT/ UFSC - SC, 2005. Disponível em: https://repositorio.ufsc.br/handle/123456789/102668 
DOI: $10.12957 / \mathrm{e}-\mathrm{mosaicos} .2020 .46139$

SILVA, Carlos; FELÍCIO, Helena Maria dos Santos. Entre o conhecimento escolar, os processos de ensino e aprendizagem e os saberes docentes: uma experiência lusobrasileira na formação de professores. Revista Eletrônica Pesquiseduca, v. 09, n. 18, p. 357-379, Maio-Ago. 2017. Disponível em:

http://periodicos.unisantos.br/index.php/pesquiseduca/article/view/716 Acesso em: 10 out. 2019

SILVA JUNIOR, César; SASSON, Sezar; CALDINI JUNIOR, Nelson. Biologia 2. $2^{\circ}$ ano, Ensino Médio, 11. ed., São Paulo: Saraiva, 2016.

SOUSA, Marta Caires de; GUIMARÃES, Ana Paula Miranda. O ensino da saúde na educação básica: desafios e possibilidades. XI Encontro Nacional de Pesquisa em Educação em Ciências - XI ENPEC Universidade Federal de Santa Catarina, Florianópolis, SC. Julho de 2017. Disponível em: http://www.abrapecnet.org.br/enpec/xi-enpec/anais/resumos/R0682-1.pdf Acesso em 11 out. 2019.

TATIBANA, L. S.; COSTA-VAL, A. P. Relação homem-animal de companhia e o papel do médico veterinário. Revista Veterinária e Zootecnia em Minas, Belo Horizonte, v. 28, n. 1, p. 12-18, 2009.

Recebido em 25 de outubro de 2019 Aceito em 19 de fevereiro de 2020

A e-Mosaicos Revista Multidisciplinar de Ensino, Pesquisa, Extensão e Cultura do Instituto de Aplicação Fernando Rodrigues da Silveira (CAp-UERJ) está disponibilizada sob uma Licença Creative Commons - Atribuição-NãoComercial 4.0 Internacional.

Os direitos autorais de todos os trabalhos publicados na revista pertencem ao(s) seu(s) autor(es) e coautor(es), com o direito de primeira publicação cedido à e-Mosaicos.

Os artigos publicados são de acesso público, de uso gratuito, com atribuição de autoria obrigatória, para aplicações de finalidade educacional e não-comercial, de acordo com o modelo de licenciamento Creative Commons adotado pela revista. 